\title{
ORIGINAL
}

\section{Clinical aspects and adrenal functions in eleven Japanese children with X-linked adrenoleukodystrophy}

\author{
Yoko Miyoshi ${ }^{1)}$, Norio Sakai ${ }^{1)}$, Yusuke Hamada ${ }^{1)}$, Makiko Tachibana ${ }^{1)}$, Yasuhiro Hasegawa ${ }^{1)}$, \\ Yuki Kiyohara $^{1)}$, Hiroyuki Yamada ${ }^{1)}$, Mari Murakami ${ }^{11}$, Hiroki Kondou ${ }^{1)}$, Shihoko Kimura-Ohba ${ }^{1)}$, \\ Junji Mine ${ }^{2)}$, Tatsuharu Sato ${ }^{3)}$, Noriko Kamio ${ }^{4)}$, Hitoshi Ueda ${ }^{5)}$, Yasuhiro Suzuki ${ }^{6}$, Masashi Shiomi ${ }^{7}$, \\ Hideaki Ohta $^{1)}$, Nobuyuki Shimozawa ${ }^{8)}$ and Keiichi Ozono ${ }^{1)}$ \\ ${ }^{1)}$ Department of Pediatrics, Osaka University Graduate School of Medicine, Osaka, Japan \\ ${ }^{2)}$ Department of Pediatrics, Hyogo College of Medicine, Hyogo, Japan \\ ${ }^{3)}$ Department of Pediatrics, Nagasaki University Hospital, Nagasaki, Japan \\ ${ }^{4)}$ Department of Pediatrics, Itami Municipal Hospital, Osaka, Japan \\ ${ }^{5)}$ Department of Pediatrics, Osaka General Medical Center, Osaka, Japan \\ ${ }^{6)}$ Division of Pediatric Neurology, Osaka Medical Center and Research Institute for Maternal and Child Health, Osaka, Japan \\ ${ }^{7)}$ Department of Pediatric Emergent Medicine and Infectious Disease Center, Osaka City General Hospital, Osaka, Japan \\ ${ }^{8)}$ Division of Genomics Research, Life Science Research Center, Gifu University, Gifu, Japan
}

\begin{abstract}
X-linked adrenoleukodystrophy (X-ALD) is a genetic disease associated with demyelination of the central nervous system, adrenocortical insufficiency and accumulation of very long chain fatty acids. It is a clinically heterogeneous disorder ranging from a severe childhood cerebral form to an asymptomatic form. The incidence in Japan is estimated to be between 1:30,000 and 1:50,000 boys as determined by a nationwide retrospective survey between 1990 and 1999, which found no cases with Addison's form. We reviewed the medical records of eleven Japanese boys with X-ALD from 1990 to 2010 in our institute. Eight patients were detected by neuropsychological abnormalities, whereas a higher prevalence of unrecognized adrenocortical insufficiency (5/11: 45\%) was observed than previously recognized. While no neurological abnormalities were demonstrated in two brothers, the elder brother had moderate Addison's disease at diagnosis and the presymptomatic younger brother progressed to Addison's disease six months after the diagnosis of X-ALD. Early detection of impaired adrenal function as well as early identification of neurologically presymptomatic patients by genetic analysis is essential for better prognosis. Addison's form might be overlooked in Japan; therefore, X-ALD should be suspected in patients with adrenocortical insufficiency.
\end{abstract}

Key words: X-linked adrenoleukodystrophy, Adrenocortical insufficiency, Addison's disease, Children, Genetic analysis

\section{X-LINKED ADRENOLEUKODYSTROPHY} (X-ALD; OMIM \#300100) is a neurodegenerative disease with demyelination of the central nervous system (CNS), adrenocortical insufficiency and the accumulation of saturated very long chain fatty acids (VLCFAs) in tissues and body fluids $[1,2]$. The patients manifest various neurological disturbances including intellectual, psychological, visual, hearing, swallowing and gait disturbances. Igarashi et al. found that

Received Jul. 5, 2010; Accepted Aug. 20, 2010 as K10E-204 Released online in J-STAGE as advance publication Sep.16, 2010

Correspondence to: Keiichi Ozono, M.D., Ph.D., Department of Pediatrics, Osaka University Graduate School of Medicine, 2-2 Yamadaoka, Suita City, Osaka, 565-0871, Japan.

E-mail: keioz@ped.med.osaka-u.ac.jp

(c) The Japan Endocrine Society cholesterol esters had an unusually high proportion of fatty acids with a chain length of 24-30 carbon atoms, rather than the usual length of less than 20, in the brain and adrenals of X-ALD patients [3]. They speculated that this might interfere with myelin formation in the CNS and steroidogenesis in the adrenals. The causative gene for X-ALD was identified by positional cloning in 1993 [4]. It is mapped to Xq28 and named ATP-binding cassette, subfamily $D$, member 1 (ABCD1; OMIM \#300371). The gene product, ALD protein (ALDP), localizes in the membrane of peroxisomes and participates in the peroxisomal degradation of VLCFAs. X-ALD primarily affects the myelin of the CNS, adrenal cortex and Leydig cells of the testes. It is clinically classified into a wide range of phe- 
notypes that are determined by the age of onset, the organs involved and the rate of progression of neurological symptoms [5], and these various clinical phenotypes were found to occur within members of the same family $[6,7]$. The childhood cerebral form is the most common and has the most severe phenotype, characterized by the progression of intellectual, visual, hearing and gait disturbances during school age. After onset, the clinical course progresses rapidly, leading to an apparently vegetative state within 2 to 4 years and thereafter to death after varying intervals. Addison's form has primary adrenal insufficiency without evidence of nervous system involvement.

Bezman et al. estimated the minimum frequency of hemizygotes in the United States to be 1:42,000 and that of hemizygotes and heterozygotes to be $1: 16,800$ [7]. Its incidence in Japan was estimated to be between 1:30,000 and 1:50,000 boys [8]. A Japanese nationwide retrospective survey between 1990 and 1999 found 286 X-ALD patients: 154 from internal medicine and neurology, 100 from pediatrics, 21 from psychiatry and 11 from special hospitals. The number of patients in Japan was estimated to be between 155 and 215, taking into account the recovery rate of the first questionnaire, and detailed data on 154 patients from 144 families were reported from 109 departments $[8,9]$. These 154 Japanese patients revealed various phenotypic distributions: childhood cerebral form $(29.9 \%)$, adrenomyeloneuropathy (AMN) form $(25.3 \%)$, adult cerebral form $(21.4 \%)$, adolescent form (9.1\%), olivo-ponto-cerebellar (OPC) form (8.4\%), presymptomatic form $(4.5 \%)$ and symptomatic female patients (1.3\%). Interestingly, Addison's form was not reported in this survey, although it has been recognized in other countries $[1,2,10]$. Here, we present eleven Japanese boys with X-ALD treated at our hospital. The aim of the present study was to assess the clinical aspects and adrenal functions of Japanese pediatric patients with X-ALD.

\section{Patients and Methods}

\section{Patients}

We reviewed the medical records of eleven Japanese boys with X-ALD followed from 1990 to 2010 in the pediatric department of Osaka University Hospital. The diagnosis of X-ALD was made on the basis of clinical manifestation, cerebral magnetic resonance imaging (MRI), accumulation of VLCFAs and genetic analysis if available. Six patients were retrospectively examined, and five were prospectively evaluated.

\section{Evaluation methods}

The clinical symptoms, social behavior, school performance and use of medications were determined from the patients and their parents. The same neurologists evaluated physical and neuropsychological findings on every visit. Laboratory data were checked at intervals of three to six months.

\section{Cerebral imaging}

Cerebral MRI was performed in all cases for diagnosis and monitoring of the disease progression [11]. Loes score (MRI severity score) was evaluated ( $0-0.5$ normal, 1-3 mild to moderate abnormal, $>3$ moderate to severe abnormal: max. score 34) [12].

\section{Laboratory determinations}

Plasma ACTH concentration was measured using immunoradiometric assay kit (Mitsubishi Chemical, Tokyo). Plasma aldosterone concentration (PAC) was determined using a commercial RIA kit (SRL, Tokyo) and plasma cortisol by chemiluminescence enzyme immunoassay (Beckman, Tokyo). Adrenal function was rated as abnormal if the baseline cortisol level was $<10 \mu \mathrm{g} / \mathrm{dL}$, baseline plasma ACTH level was $>100 \mathrm{pg} / \mathrm{mL}$ or cortisol response to ACTH stimulation test was suboptimal. Mineralcorticoid deficiency was considered to be present when the baseline PAC level was $<30 \mathrm{pg} / \mathrm{mL}$ (at supine position) or PAC response to ACTH stimulation test was suboptimal. The response to stimulation with exogenous ACTH $(250 \mu \mathrm{g} /$ $\mathrm{m}^{2}$ ) was considered normal if a cortisol level of $>20$ $\mu \mathrm{g} / \mathrm{dL}$ was observed with more than twofold increment in PAC level. These hormones were measured in the morning to avoid diurnal variation, and $\mathrm{ACTH}$ stimulation test was performed during hospitalization.

\section{Analyses of the plasma VLCFA levels and ABCD1 gene}

Plasma VLCFA levels were determined by capillary gas chromatography-mass spectrometry. Analyses of the plasma VLCFA levels including lignoceric acid (C24:0), pentacosanoic acid (C25:0), hexacosanoic acid (C26:0) and their ratios to behenic acid (C22:0) were used to confirm the diagnosis of X-ALD [13]. DNA analysis for the $A B C D 1$ gene was performed at Gifu University after obtaining informed consent from 
Table 1 Profile of eleven X-ALD patients (1).

\begin{tabular}{|c|c|c|c|c|c|c|c|c|}
\hline $\begin{array}{l}\text { Case } \\
\text { No. }\end{array}$ & $\begin{array}{c}\text { Age at } \\
\text { onset }\end{array}$ & $\begin{array}{c}\text { Age at } \\
\text { diagnosis }\end{array}$ & $\begin{array}{l}\text { Present } \\
\text { age }\end{array}$ & Gender & Phenotype & Initial symptom & Mother & $\begin{array}{c}\text { Genetic analysis of } \\
A B C D 1 \text { gene }\end{array}$ \\
\hline \multicolumn{9}{|c|}{ Retrospective cases } \\
\hline 1 & 2 & 2 & 5 & male & olivo-ponto-cerebellar & gait disturbance & normal & c. $1201 \mathrm{C}>\mathrm{T}$ \\
\hline 2 & 5 & 5 & 13 & male & childhood cerebral & visual disturbance & carrier & c. $347 \mathrm{G}>\mathrm{A}$ \\
\hline 3 & 6 & 6 & dead & male & childhood cerebral & visual disturbance & $\begin{array}{l}\text { carrier } \\
(\mathrm{AMN})\end{array}$ & NA \\
\hline 4 & 7 & 7 & 13 & male & childhood cerebral & visual disturbance & carrier & NA \\
\hline 5 & 7 & 7 & 11 & male & childhood cerebral & gait disturbance & carrier & c. $1661 \mathrm{G}>\mathrm{A}$ \\
\hline 6 & 9 & 9 & 11 & male & childhood cerebral & convulsions & carrier & c. $1780+1163-$ del $6273(\mathrm{bp})$ \\
\hline \multicolumn{9}{|c|}{ Prospective cases } \\
\hline $7^{*}$ & 6 & 7 & 8 & male & Addison's disease & skin pigmentation & carrier & c. 2010 GCTAC $>$ TAT \\
\hline $8^{*}$ & 6 & 6 & 7 & male & presymptomatic & no symptom & carrier & c. 2010 GCTAC $>$ TAT \\
\hline 9 & 7 & 8 & 8 & male & childhood cerebral & $\begin{array}{c}\text { abnormality in } \\
\text { cerebral MRI }\end{array}$ & NA & c. $2014 \mathrm{C}>\mathrm{T}$ \\
\hline 10 & 8 & 8 & 8 & male & childhood cerebral & gait disturbance & carrier & c. $1850 \mathrm{G}>\mathrm{A}$ \\
\hline $11^{*}$ & 9 & 11 & 12 & male & childhood cerebral & $\begin{array}{c}\text { intellectual and } \\
\text { behavioral changes }\end{array}$ & carrier & c. 2010 GCTAC $>$ TAT \\
\hline
\end{tabular}

NA: not available, *relatives

the parents. Family members were also examined for VLCFA levels and $A B C D 1$ genes after obtaining informed consent for genetic counseling.

\section{Results}

\section{Physical status}

Eleven Japanese males with X-ALD were included in this study (Table 1). Their ages ranged from 5 to 13 years. One boy (case 3 ) died from pneumonia at the age of 12 years. Neuropsychological abnormalities were observed as initial symptoms in eight patients $(73 \%)$. These initial symptoms were as follows: gait disturbance in three (cases 1, 5 and 10); visual disturbance in three (cases 2, 3 and 4); convulsions in one (case 6); school failure, intellectual and behavioral changes in 1 (case 11). One boy (case 9) was incidentally identified by abnormality of cerebral MRI during acute encephalitis with Rota-virus infection. Two brothers (cases 7 and 8) with no neurological abnormalities were identified by genetic analysis of the proband (case 11) to have the childhood cerebral form, whereas the elder brother had already suffered moderate skin pigmentation and general fatigue. Their ages at diagnosis of X-ALD ranged from 2 to 11 years. The intervals between the initial symptom and diagnosis were all within two years: less than 1 year
$(\mathrm{N}=8), 1$ year $(\mathrm{N}=2)$ and 2 years $(\mathrm{N}=1)$. Full-scale intelligence quotient (FIQ) score of the patients at diagnosis ranged from 58 to 107 (Table 2). Performance IQ (PIQ) was not evaluated in cases 2 and 4 because of visual disturbance, although verbal IQ (VIQ) was reserved. Two patients were evaluated by developmental quotient (DQ), with scores ranging from 63 to 89 (Table 2).

\section{Clinical classifications}

The patients were clinically classified into four types: childhood cerebral form $(\mathrm{N}=8)$, OPC form $(\mathrm{N}=1)$, Addison's form $(\mathrm{N}=1)$ and presymptomatic form $(\mathrm{N}=1)$ (Table 1). Three cases (cases 7, 8 and 11) were relatives; two brothers (cases 7 and 8 ) and their maternal cousin (case 11). Their mothers were identified as the carriers, and various clinical phenotypes were observed within this pedigree. Two male maternal relatives had already died and were suspected of having had the childhood cerebral form and the adult cerebral form. One patient (case 3) with the childhood cerebral form had a mother with the AMN form, who had complained of paralysis in her lower legs since the age of 26 years.

\section{Cerebral MRI}

MRI scans of patients with the childhood cere- 
Table 2 Profile of eleven X-ALD patients (2).

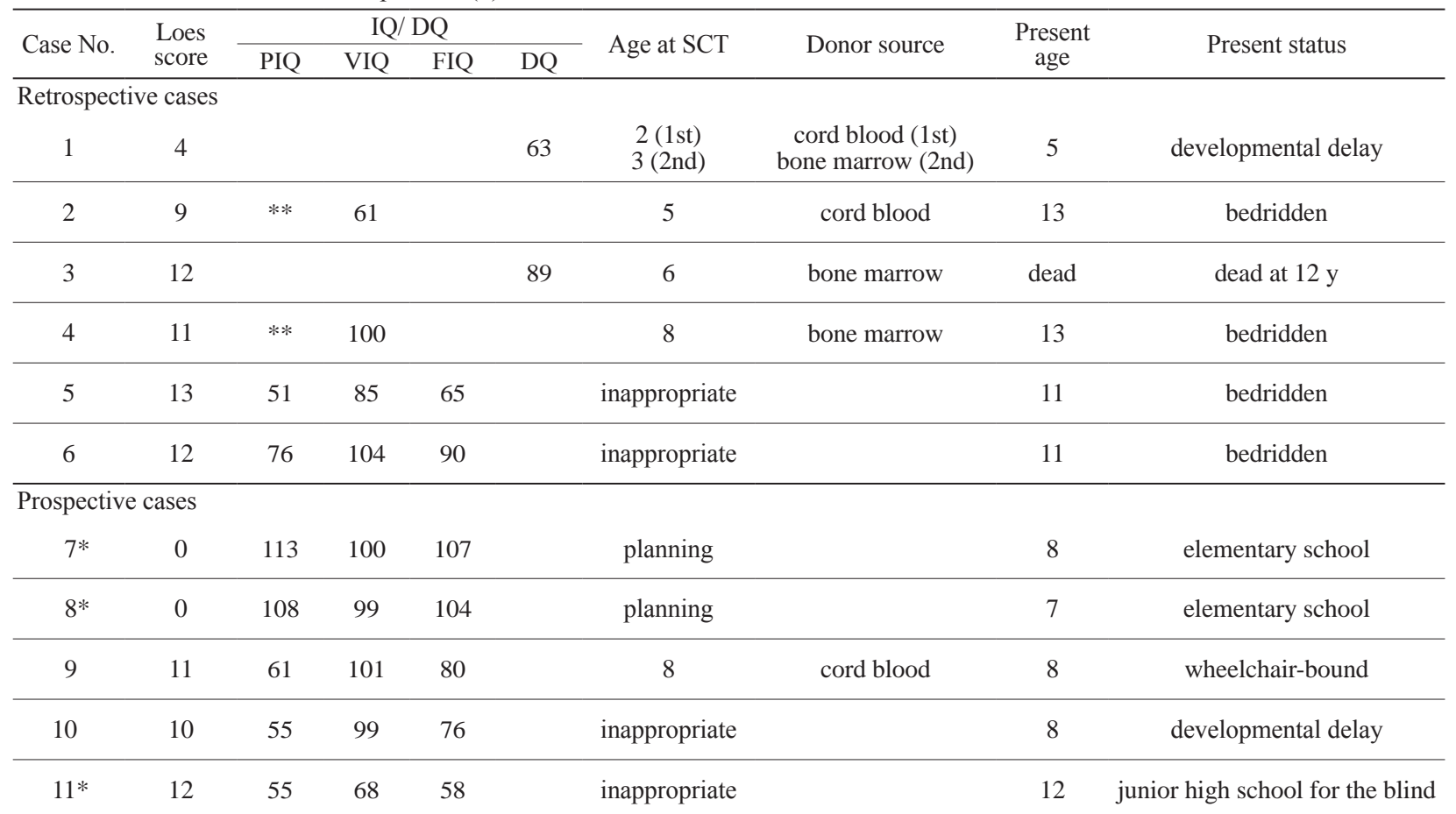

NA: not available, SCT: stem cell transplantation, *relatives, $* *$ impossible because of vision impairment

Table 3 Adrenal functions of eleven X-ALD patients.

\begin{tabular}{|c|c|c|c|c|c|c|c|}
\hline \multirow[b]{2}{*}{ Case No. } & \multicolumn{4}{|c|}{ Adrenal function at diagnosis } & \multicolumn{3}{|c|}{ Present status } \\
\hline & $\begin{array}{c}\text { ACTH } \\
(\mathrm{pg} / \mathrm{mL})\end{array}$ & $\begin{array}{l}\text { Cortisol } \\
(\mu \mathrm{g} / \mathrm{dL})\end{array}$ & $\begin{array}{c}\text { Rapid ACTH } \\
\text { basal/peak cortisol }\end{array}$ & $\begin{array}{c}\text { Rapid ACTH } \\
\text { basal/ peak aldosterone }\end{array}$ & Steroid replacement & $\begin{array}{c}\mathrm{ACTH} \\
(\mathrm{pg} / \mathrm{mL})\end{array}$ & $\begin{array}{l}\text { Cortisol } \\
(\mu \mathrm{g} / \mathrm{dL})\end{array}$ \\
\hline \multicolumn{8}{|c|}{ Retrospective cases } \\
\hline 1 & 63 & 7.3 & $16.3 / 24.4$ & NA & prednisone $2.5 \mathrm{mg}$ & 16 & 1.6 \\
\hline 2 & 1558 & 4.9 & $4.64 / 5.27$ & NA & $\begin{array}{l}\text { dexamethasone } 1 \mathrm{mg} \\
\text { fluorocortisone } 0.15 \mathrm{mg}\end{array}$ & 353 & 0.02 \\
\hline 3 & 49.9 & 10.9 & $7.4 / 26.9$ & NA & $\begin{array}{c}\text { none } \\
\text { (final status) }\end{array}$ & $\begin{array}{c}127.2 \\
\text { (final status) }\end{array}$ & $\begin{array}{c}11.7 \\
\text { (final status) }\end{array}$ \\
\hline 4 & 33 & NA & $6.8 / 20.8$ & NA & none & 28 & 6.6 \\
\hline 5 & 146 & 8.4 & $8.4 / 17.6$ & NA & hydrocortisone 15 mg & 8 & 3.6 \\
\hline 6 & 28.4 & 16.1 & $16.1 / 26.1$ & NA & none & 100 & 17.8 \\
\hline \multicolumn{8}{|c|}{ Prospective cases } \\
\hline $7^{*}$ & 1190 & 5.9 & $5.3 / 5.7$ & $40 / 54$ & hydrocortisone 10 mg & 727 & 1.9 \\
\hline $8^{*}$ & 61 & 6.4 & $5.6 / 20.5$ & $67 / 205$ & hydrocortisone 5 mg & 235 & 11.6 \\
\hline 9 & 1043 & 8.4 & $8.8 / 8.9$ & $146 / 213$ & hydrocortisone 30 mg & 42 & 3.7 \\
\hline 10 & 81 & 13.4 & $6.9 / 23.5$ & $110 / 368$ & none & 21 & 8.0 \\
\hline $11^{*}$ & 614 & 8.1 & $5.8 / 8.3$ & $77 / 79$ & hydrocortisone 12 mg & 507 & 8.8 \\
\hline
\end{tabular}

NA: not available, *relatives 
bral form showed characteristic white matter lesions. These lesions symmetrically involved the periventricular parietooccipital white matter associated with huge inflammatory demyelination. Loes score at diagnosis ranged from 0 to 13 (Table 2).

\section{Laboratory studies}

Adrenocortical functions were rated as abnormal at diagnosis with X-ALD in five cases (cases 2, 5, 7, 9 and 11): baseline plasma ACTH level $>100 \mathrm{pg} / \mathrm{mL}$ $(146-1558 \mathrm{pg} / \mathrm{mL})$ as well as suboptimal cortisol response to ACTH stimulation test $(5.27-17.6 \mu \mathrm{g} / \mathrm{dL})$ (Table 3). Serum studies, including electrolytes, glucose and liver functions, yielded normal results in all patients. Baseline PAC levels were normal for patient age. PAC response to ACTH stimulation was evaluated in five prospective cases; two patients (cases 7 and 11) yielded suboptimal PAC response. Baseline renin (PRA) levels were 4.0 (case 7) and $3.0 \mathrm{ng} / \mathrm{mL} / \mathrm{h}$ (case 11). The adrenocortical functions worsened in two patients during follow-up: 6 years after the diagnosis of the childhood cerebral form or five years after stem cell transplantation (SCT) in case 3, and 6 months after the diagnosis of the presymptomatic form in case 8 . Testosterone deficiency was not obvious in our pediatric patients.

\section{Analysis of the plasma VLCFA levels and ABCD1 gene}

All patients and their family members (all but one mother, one grandmother and two sisters) revealed elevation of VLCFA levels and the examined ratios (C24:0, C25:0, C26:0 / C22:0). This elevation was not observed in the parents and younger brother of one sporadic case (case 1). Nine patients had mutations in $A B C D 1$ gene, which had all been previously reported with the exceptions of c.1780+1163- del 6273 (bp) and c. 2010 GCTAC>TAT (Table 1). They had the same mutations as their family members, with the exception of one sporadic case (case 1). The parents of case 9 declined to undergo genetic analysis of the family members although none of the family members had revealed neurological abnormalities. Two retrospectively analyzed patients (cases 3 and 4 ) could not be genetically analyzed.

\section{Treatments}

\section{Steroid replacement}

Steroid replacement therapy for adrenocortical in- sufficiency was undertaken in seven patients (64\%): from the diagnosis of X-ALD in five, from half a year after the diagnosis in one (case 8), and from the SCT procedure in one patient (case 1) (Table 3). The dosage has been adjusted and gradually increased according to serum morning cortisol, ACTH and 24-hour urinary free cortisol excretion. The present dosage varies with the individual: 5-30 mg of hydrocortisone $(\mathrm{N}=5)$, $1 \mathrm{mg}$ of dexamethasone and $0.15 \mathrm{mg}$ of fludrocortisones $(\mathrm{N}=1)$ and $2.5 \mathrm{mg}$ of prednisone $(\mathrm{N}=1)$.

\section{Stem cell transplantation and other medical therapies}

Five patients had received allogeneic SCT at the age of 2-8 years, all within one year of the diagnosis with X-ALD (Table 2). The stem cell source was bone marrow (cases 3 and 4), cord blood (cases 2 and 9) or both (case 1). The transplanted cord blood cells were rejected in two patients (cases 1 and 9); one patient (case 1) received a second transplantation from HLA-matched allogenic bone marrow. The neurological prognosis after SCT was as follows: rapidly progressed and worsened after the SCT procedure $(\mathrm{N}=4)$ or slowly progressed and stabilized $(\mathrm{N}=1)$. Four neurologically advanced patients were assessed as too advanced to receive SCT. For two neurologically normal but affected brothers (cases 7 and 8), HLA-matched stem cell units had been discovered in the cord blood bank. They had been evaluated by neuropsychological tests and cerebral MRI every six months for early detection of cerebral involvement and appropriate timing for SCT.

Lorenzo's oil was recommended for all patients although its effect was not clear. Adequate nutrition was given by nasogastric or gastrostomy feeding in four patients.

\section{Prognosis after the diagnosis}

One bedridden patient (case 3) died at the age of 12 owing to pneumonia six years after the diagnosis or five years after the SCT. Ten patients are alive: bedridden $(\mathrm{N}=4)$, with developmental delay $(\mathrm{N}=2)$, in a wheelchair $(\mathrm{N}=1)$, a student of a junior high school for the blind $(\mathrm{N}=1)$ and elementary school students $(\mathrm{N}=2)$ (Table 2).

\section{Discussion}

$\mathrm{X}$-ALD is an X-linked disorder, which is caused by a mutation in the $A B C D 1$ gene encoding ALDP 
(http://www.X-ald.nl/) [1.2]. ALDP participates in the peroxisomal degradation of VLCFAs in oligodendrocytes and microglia, and its deficiency disrupts myelin maintenance by these cells [14]. The development of assays to detect the accumulation of VLCFAs in blood, red blood cells, fibroblasts and amniocytes enabled accurate diagnosis of X-ALD $[15,16]$. Indeed, we were able to correctly diagnose all patients in this study from the assay of their sera.

A nationwide retrospective survey in Japan between 1990 and 1999 found 286 X-ALD patients [8]. In a second survey, precise data on 154 patients from 144 families were reported. Interestingly, Addison's form, that is, adrenal insufficiency without neurologic disease, was not reported in this Japanese nationwide survey. In our present study, eleven Japanese cases of childhood X-ALD were divided into four clinical types: childhood cerebral form $(\mathrm{N}=8)$, OPC form $(\mathrm{N}=1)$, Addison's form $(\mathrm{N}=1)$ and presymptomatic form $(\mathrm{N}=1)$. Similar to the previous reports, there was no correlation between $A B C D 1$ gene mutations and clinical phenotypes. Their carrier mothers did not manifest neurological abnormalities, with the exception of one mother with the AMN form. In this survey we found unrecognized adrenocortical insufficiency $(5 / 11: 45 \%)$, glucocorticoid insufficiency (5/11: 45\%) and suboptimal PAC response (2/5: 40\%). Glucocorticoids are usually more affected than mineralcorticoids, but the precise mechanism of adrenocortical insufficiency has yet to be clarified. The exact prevalence of Addison's form within X-ALD as well as the frequency of X-ALD among male patients with idiopathic Addison's disease has not been specified $[10,17,18]$. Perry et al. studied the causes of primary adrenal insufficiency in 103 patients (48 boys) at the Sainte-Justine Hospital [19]. They identified congenital adrenal hyperplasia as the most frequent etiology $(71.8 \%)$, but non-CAH etiologies accounted for $28.2 \%$, of which four males $(3.9 \%)$ had X-ALD. Ronghe et al. described that 11 out of 13 cases of children with Addison's disease were caused by underlying X-ALD in Southwest England [20]. Dubey et al. showed that approximately $80 \%$ of 49 asymptomatic boys with X-ALD, identified by plasma VLCFA screening of at-risk relatives, already had biochemical evidence of clinically silent adrenal insufficiency [21]. In contrast, Addison's form without neurological symptoms was not found in 154 X-ALD patients registered in a nationwide survey in Japan between 1990 and 1999 [8], and only 5 of 145 neurologically disturbed X-ALD patients manifested adrenal dysfunction as an initial symptom [9]. The Addison's form might have been overlooked in Japan because X-ALD was often associated with long intervals, sometimes decades, between the appearance of Addison's disease and neurological symptoms. Interestingly, many $\mathrm{X}$-ALD adult patients develop testosterone deficiency and azoospermia, whereas testicular dysfunction was not apparent in our pediatric patients. Since the present result was obtained from a small number of patients, there may be some limitations in the analysis. The next nationwide study should evaluate more accurately the rate of adrenal insufficiency in Japanese X-ALD.

Steroid replacement therapy is the only effective and readily available therapy for X-ALD. ALDP exists in the adrenal cortex but not in the adrenal medulla, which is in line with the pathological findings of lamellae and lamellar-lipid profiles shown to contain VLCFA esterified to cholesterol in adrenocortical cells $[22,23]$. Allogeneic SCT is the only fundamentally effective therapy for neurological pathology to date, if provided at an early stage of brain lesions [24, 25]. It appears to provide benefits only for those patients who have little or no CNS involvement and have a stem cell donor who is well matched with regard to HLA $[26,27]$. Patients with Addison's form were not considered appropriate for SCT because steroid replacement therapy was safer than SCT procedure and the damage to the adrenal gland might not be reversible. To the best of our knowledge, the adrenal function of $\mathrm{X}$-ALD at post-SCT has not been reported. The adrenocortical function in case 3 worsened during followup: 6 years after the diagnosis of the childhood cerebral form or five years after SCT. Furthermore, all of our patients with adrenocortical insufficiency have been supplemented after SCT (Table 3). The worsening of adrenal function after SCT was assumed to be due to progression of X-ALD because it is unlikely that the conditioning regimen of SCT for ALD was so intensive as to cause adrenal insufficiency [26]. The long-term benefits of SCT in X-ALD might be mediated by the replacement of brain microglial cells derived from donor bone marrow myelo-monocytic cells [28]. Donor-derived cells in the brain after cord blood SCT in a Hunter disease patient were recently identified [29]. It is also possible that benefit might be derived from the combination of immunosuppression and re- 
constitution by a new set of immune-regulating cells, which ameliorate the inflammatory effects of X-ALD or may serve as an exogenous source of corrective factors to degrade VLCFA and/or to provide the favorable modifier substance. Because cerebral X-ALD is a progressive disorder, all patients with demyelination can be expected to exhibit further injury to myelin before stabilization occurs after SCT. Indeed, our patients experienced neurological deterioration into advanced cerebral disease after the procedure. However, the indications for SCT in presymptomatic X-ALD should be carefully considered, as it is still impossible to predict their clinical phenotypes and there are still risks associated with the SCT procedure. As a biological marker is unavailable for prediction of the onset of cerebral demyelination, careful monitoring of neurological examination and cerebral MRI are the only tools to identify patients who will benefit from SCT.
Traditional pharmacological approaches including Lorenzo's oil combined with a dietary regimen and immunosuppression are of little, if any, benefit [30]. Other specific therapies are under evaluation including gene replacement and pharmacological gene therapy $[31,32]$. Recently, Cartier et al. initiated a lentiviralmediated gene therapy of hematopoietic stem cells in two X-ALD patients for whom there were no matched donors for SCT [32].

In conclusion, we detected a higher prevalence of unrecognized adrenocortical insufficiency in eleven Japanese children with X-ALD than previously thought. Endocrinological follow-up of potential adrenocortical insufficiency is essential for patients with $\mathrm{X}-\mathrm{ALD}$, and early detection of presymptomatic patients is also important for morbidity and prognosis. Larger studies are required to evaluate more accurately the adrenal functions in Japanese X-ALD.

\section{References}

1. Moser HW, Mahmood A, Raymond GV (2007) X-linked adrenoleukodystrophy. Nat Clin Pract Neurol 3:140-151.

2. Berger J, Gartner J(2006) X-linked adrenoleukodystrophy: clinical, biochemical and pathogenetic aspects. Biochim Biophys Acta 1763: 1721-1732.

3. Igarashi M, Schaumburg HH, Powers J, Kishimoto Y, Kolodny EH, Suzuki K (1976) Fatty acid abnormality in adrenoleukodystrophy. J Neurochem 26: 851-860.

4. Mosser J, Douar AM, Sarde CO, Kioschis P, Feil R, Moser H, Poustka AM, Mandel JL, Aubourg P (1993) Putative X-linked adrenoleukodystrophy gene shares unexpected homology with ABC transporters. Nature 361: 726-730.

5. Moser HW, Loes DJ, Melhem ER, Raymond GV, Bezman L, Cox CS, Lu SE (2000) X-linked adrenoleukodystrophy: overview and prognosis as a function of age and brain magnetic resonance imaging abnormality: a study involving 372 patients. Neuropediatrics 31: 227-239.

6. Bezman L, Moser HW (1998) Incidence of X-linked adrenoleukodystrophy and the relative frequency of its phenotypes. Am J Med Genet 76: 415-419.

7. Bezman L, Moser AB, Raymond GV, Rinaldo P, Watkins PA, Smith KD, Kass NE, Moser HW (2001) Adrenoleukodystrophy: incidence, new mutation rate, and results of extended family screening. Ann Neurol 49: 512-517.

8. Takemoto Y, Suzuki Y, Tamakoshi A, Onodera O, Tsuji S, Hashimoto T, Shimozawa N, Orii T, Kondo N (2002)
Epidemiology of X-linked adrenoleukodystrophy in Japan. J Hum Genet 47: 590-593.

9. Suzuki Y, Takemoto Y, Shimozawa N, Imanaka T, Kato S, Furuya H, Kaga M, Kato K, Hashimoto N, Onodera O, Tsuji S (2005) Natural history of X-linked adrenoleukodystrophy in Japan. Brain Dev 27: 353-357.

10. Laureti S, Casucci G, Santeusanio F, Angeletti G, Aubourg P, Brunetti P (1996) X-linked adrenoleukodystrophy is a frequent cause of idiopathic Addison's disease in young adult male patients. J Clin Endocr Metab 81: 470-474.

11. Loes DJ, Fatemi A, Melhem ER, Gupte N, Bezman L, Moser HW, Raymond GV (2003) Analysis of MRI patterns aids prediction of progression in X-linked adrenoleukodystrophy. Neurology 61: 369-374.

12. Loes DJ, Hite S, Moser H, Stillman AE, Shapiro E, Lockman L, Latchaw RE, Krivit W (1994) Adrenoleukodystrophy: a scoring method for brain MR observations. Am J Neuroradiol 15: 1761-1766.

13. Takemoto Y, Suzuki Y, Horibe R, Shimozawa N, Wanders RJ, Kondo N (2003) Gas chromatography/ mass spectrometry analysis of very long chain fatty acids, docosahexaenoic acid, phytanic acid and plasmalogen for the screening of peroxisomal disorders. Brain Dev 25: 481-487.

14. Eichler FS, Ren JQ, Cossoy M, Rietsch AM, Nagpal S, Moser AB, Frosch MP, Ransohoff RM (2008) Is microglial apoptosis an early pathogenic change in cerebral X-linked adrenoleukodystrophy? Ann Neurol 63: 729742. 
15. Singh I, Moser AE, Moser HW, Kishimoto Y (1984) Adrenoleukodystrophy: impaired oxidation of very long chain fatty acids in white blood cells, cultured skin fibroblasts, and amniocytes. Pediatr Res 18: 286290.

16. Moser AB, Kreiter N, Bezman L, Lu S, Raymond GV, Naidu S, Moser HW (1999) Plasma very long chain fatty acids in 3,000 peroxisome disease patients and 29,000 controls. Ann Neurol 45: 100-110.

17. Kong MF, Jeffcoate W (1994) Eighty-six cases of Addison's disease. Clin Endocrinol (Oxf) 41: 757-761.

18. Jorge P, Quelhas D, Oliveira P, Pinto R, Nogueira A (1994) X-linked adrenoleukodystrophy in patients with idiopathic Addison disease. Eur J Pediatr 153: 594597.

19. Perry R, Kecha O, Paquette J, Huot C, Van Vliet G, Deal C (2005) Primary adrenal insufficiency in children: twenty years experience at the Sainte-Justine Hospital, Montreal. J Clin Endocrinol Metab 90: 32433250.

20. Ronghe MD, Barton J, Jardine PE, Crowne EC, Webster MH, Armitage M, Allen JT, Steward CG (2002) The importance of testing for adrenoleucodystrophy in males with idiopathic Addison's disease. Arch Dis Child 86: 185-189.

21. Dubey P, Raymond GV, Moser AB, Kharkar S, Bezman L, Moser HW (2005) Adrenal insufficiency in asymptomatic adrenoleukodystrophy patients identified by very long-chain fatty acid screening. J Pediatr 146: 528-532.

22. Powers JM, Moser HW, Moser AB, Schaumburg HH (1982) Fetal adrenoleukodystrophy: the significance of pathologic lesions in adrenal gland and testis. Hum Pathol 13: 1013-1019.

23. Powers JM, Schaumburg HH (1974) Adrenoleukodystrophy (sex-linked Schilder's disease). A pathogenetic hypothesis based on ultrastructural lesions in adrenal cortex, peripheral nerve and testis. Am J Pathol 76: 481-491.

24. Aubourg P, Blanche S, Jambaque I, Rocchiccioli F, Kalifa G, Naud-Saudreau C, Rolland MO, Debre M, Chaussain JL, Griscelli C, Fischer A, Bougneres PF (1990) Reversal of early neurologic and neuroradiologic manifestations of X-linked adrenoleukodystrophy by bone marrow transplantation. New Eng J Med 322: 1860-1866.
25. Shapiro E, Krivit W, Lockman L, Jambaqué I, Peters C, Cowan M, Harris R, Blanche S, Bordigoni P, Loes D, Ziegler R, Crittenden M, Ris D, Berg B, Cox C, Moser H, Fischer A, Aubourg P (2000) Long-term effect of bone-marrow transplantation for childhood-onset cerebral X-linked adrenoleukodystrophy. Lancet 356: 713718.

26. Peters C, Charnas LR, Tan Y, Ziegler RS, Shapiro EG, DeFor T, Grewal SS, Orchard PJ, Abel SL, Goldman AI, Ramsay NK, Dusenbery KE, Loes DJ, Lockman LA, Kato S, Aubourg PR, Moser HW, Krivit W (2004) Cerebral X-linked adrenoleukodystrophy: the international hematopoietic cell transplantation experience from 1982 to 1999. Blood 104: 881-888.

27. Mahmood A, Raymond GV, Dubey P, Peters C, Moser HW (2007) Survival analysis of haematopoietic cell transplantation for childhood cerebral X-linked adrenoleukodystrophy: a comparison study. Lancet Neurol 6: 687-692.

28. Eglitis MA, Mezey E (1997) Hematopoietic cells differentiate into both microglia and macroglia in the brains of adult mice. Proc Natl Acad Sci U S A 94: 4080-4085.

29. Araya K, Sakai N, Mohri I, Kagitani-Shimono K, Okinaga T, Hashii Y, Ohta H, Nakamichi I, Aozasa K, Taniike M, Ozono K (2009) Localized donor cells in brain of a Hunter disease patient after cord blood stem cell transplantation. Mol Genet Metab 98: 255-263.

30. Moser HW, Moser AB, Hollandsworth K, Brereton NH, Raymond GV(2007) “Lorenzo's oil” therapy for $\mathrm{X}$-linked adrenoleukodystrophy: rationale and current assessment of efficacy. J Mol Neurosci 33:105-113.

31. Engelen M, Ofman R, Dijkgraaf MG, Hijzen M, van der Wardt LA, van Geel BM, de Visser M, Wanders RJ, Poll-The BT, Kemp S(2010) Lovastatin in X-linked adrenoleukodystrophy. $N$ Engl J Med 362: 276-277.

32. Cartier N, Hacein-Bey-Abina S, Bartholomae CC, Veres G, Schmidt M, Kutschera I, Vidaud M, Abel U, Dal-Cortivo L, Caccavelli L, Mahlaoui N, Kiermer V, Mittelstaedt D, Bellesme C, Lahlou N, Lefrère F, Blanche S, Audit M, Payen E, Leboulch P, l'Homme $\mathrm{B}$, Bougnères $\mathrm{P}$, Von Kalle $\mathrm{C}$, Fischer $\mathrm{A}$, CavazzanaCalvo M, Aubourg P (2009) Hematopoietic stem cell gene therapy with a lentiviral vector in X-linked adrenoleukodystrophy. Science 326: 818-823. 